\title{
To err is human - and let's not forget it
}

Previously published at www.cmaj.ca

A lexander Pope, poet of the Enlightenment, lent a famous line from his 1711 treatise $A n$ Essay on Criticism to the US Institutes of Medicine's report on patient safety: To Err is Human. ${ }^{1}$ The remainder of the line, "to forgive divine," would have further reinforced the report's message. Those who made mistakes should neither be blamed nor punished, it argues, instead, to look at the system.

The institute's 1999 report was both a tipping and a turning point: It revealed that there were an estimated 100000 preventable patient deaths a year in the United States. In Canada, researchers later estimated there were 70000 preventable adverse events annually in hospitalized patients and preventable mortalities in the range of 9000 to $24000 .^{2}$ The magnitude of the problem was unmasked and the new century ushered in an era of openness. The dramatic change that occurred in removing the focus from individuals led to closer examination of health care systems and how they fail us.

The decade that followed perhaps exceeded the wildest expectations of the pioneers of the modern patient-safety movement. Studies throughout the world confirmed that the US had it right: About $10 \%$ of all patients entering hospitals suffer an adverse event and significant numbers of them die. ${ }^{2}$ Just having these numbers out in the open was critically important, and action followed remarkably quickly: conferences, research initiatives, fellowships and chairs, and patient-safety officers. The Canadian Patient Safety Institute was established in 2004. In the United States, a whole industry around patient safety sprang up. This is all very commendable.

However, the focus may have been taken prematurely off the individual. The health care system is designed by humans and error is inevitable as long as humans are involved. Personality, gender, motivation and other constitutional factors will give rise to variation, which

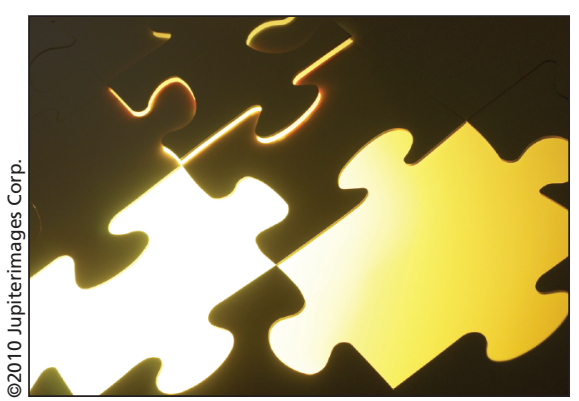

in turn begets uncertainty and unpredictability and, inevitably, error. The institutes' report may have given us a convenient out, deflecting the blame toward the system. Now we appear to have settled on restricting our focus to the obvious and tangible. Instead, we should be looking at better ways to understand the characteristics of human performance in the health care setting. Psychologists have already unearthed an abundance of information that awaits our application.

Elsewhere in his essay, Pope stresses the many human factors that lead to bad outcomes: overconfidence, tunnel vision, bias, prejudice and inconsistency, among others, and exhorts us to combine "good nature and good sense" in our judgment. Modern cognitive psychologists might translate the latter as steering clear of a multitude of cognitive and affective biases, and using critical reasoning and thinking to arrive at sound decisions. Good decision-making and judgment would go some way toward reducing the $15 \%$ or so errors that are made in the diagnostic process and the mismanagement that follows. ${ }^{3}$

Diagnostic failure predominantly reflects a failure in individual thinking, ${ }^{3}$ although the system also may be culpable. It occurs when the disease has become manifest and, despite having adequate information, the clinician fails to make the correct diagnosis. Many things can go wrong in looking after patients, but diagnostic failure may be the worst of them. Diagnostic error is high-hanging fruit and while the processes that underlie it are mostly invisible and intangible, they will need addressing systematically.

It is rarely a knowledge deficit that leads to a diagnostic error; more commonly, it is flawed thinking. ${ }^{3}$ Nevertheless, few medical schools put an emphasis on critical thinking. This reflects a lack of critical thinking by medical educators. We should not assume that medical undergraduates and residents will develop good critical-thinking skills. Many will not and the curriculum needs to provide emphasis and direction. Knowledge may be ephemeral in medicine, but critical thinking is for life.

Thinking, feeling and reasoning are not system properties; they are very human. With some of the major hurdles behind us in patient safety, we should now be looking more closely at our most precious resource - humans and their complex cognitive and affective behaviours. Error that is not egregious or due to indolence should be forgiven, but it needs to be studied as a phenomenon in its own right.

\section{Pat Croskerry MD PhD}

Professor

Department of Emergency Medicine

Dalhousie University

Halifax, NS

Dr. Croskerry is the lead author of Patient Safety in Emergency Medicine (review: CMAJ 2010;182:E52) and a founder of the Halifax series of Symposia on Patient Safety.

\section{REFERENCES}

1. Kohn LT, Corrigan JM, Donaldson MS, editors. To err is human: building a safer system. Washington (DC): National Academy Press; 1999.

2. Baker GR, Norton PG, Flintoft V, et al. The Canadian Adverse Events Study: the incidence of adverse events among hospital patients in Canada. CMAJ 2004;170:1678-86.

3. Graber ML, Franklin N, Gordon R. Diagnostic error in internal medicine. Arch Intern Med 2005; 165:1493-9.

Have you got an opinion about this article? Post your views at www.cmaj.ca. Potential Salon contributors are welcome to send a query to salon@ cmaj.ca. 